\title{
Variability of tidal breathing parameters in preterm infants and associations with respiratory morbidity during the first year of life: a cohort-study
}

Jakob Usemann ${ }^{1,2 *}$, Andrea Suter ${ }^{1 *}$, Emanuela Zannin ${ }^{1,3}$, Elena Proietti1,2, Sotirios Fouzas ${ }^{4}$, Sven Schulzke ${ }^{1}$, Philipp Latzin², and Urs Frey on behalf of the BILD study group.

'University of Basel Children's Hospital (UKBB), Basel, Switzerland, ${ }^{2}$ Pediatric Respiratory Medicine, Department of Pediatrics, Inselspital, Bern University Hospital, Switzerland, ${ }^{3}$ Dipartimento di Elettronica, Informazione e Bioingegneria, Politecnico di Milano University, Italy. ${ }^{4}$ Pediatric

Respiratory Unit, University Hospital of Patras, Greece. *These authors contributed equally.

- Preterm infants with bronchopulmonary dysplasia (BPD) are at increased risk for respiratory morbidity during early childhood.

- Non-invasive markers to identify infants at risk would be of great value for the clinical management.

- Compared to healthy infants, variability of tidal volume $\left(\mathrm{V}_{\mathrm{T}}\right)$ and capnographic parameters is lower in preterm infants, and particularly in those with BPD.

- The aims of the present study were, to investigate whether: 1) variability of $V_{T}$ and capnographic parameters, is associated with subsequent respiratory morbidity; 2) these variability parameters can enhance the poor predictive power of the standard BPD severity classification.

\section{Experimental design \& methods}

- Preterm infants $(<37$ weeks) performed lung function measurements at 44 weeks post-menstrual age. Measurements were done according to ATS/ERS standards, using the Exhalyzer D (EcoMedics AG, Dürnten, Switzerland), which incorporates an ultrasonic flowmeter and a mainstream $\mathrm{CO}_{2}$ sensor.

- We assessed the expired $\mathrm{CO}_{2}$ volume per breath $\left(\mathrm{V}_{\mathrm{E}, \mathrm{CO} 2}\right)$, and the $\mathrm{CO}_{2}$ elimination per minute $\left(\mathrm{MV}_{\mathrm{CO} 2}\right)$, and the coefficient of variation $(\mathrm{CV})$ of these parameters was calculated. The relative breath-to-breath change of $\mathrm{V}_{\mathrm{E}, \mathrm{CO} 2}\left(\Delta \mathrm{V}_{\mathrm{E}, \mathrm{CO} 2}\right)$ was plotted against the change of $\mathrm{V}_{T}$ $\left(\Delta \mathrm{V}_{\mathrm{T}}\right)$ and the slope of the regression line was computed (slope $\left.\Delta \mathrm{V}_{\mathrm{E}, \mathrm{CO} 2} / \Delta \mathrm{V}_{\mathrm{T}}\right)$. This slope describes the variability of $\mathrm{CO}_{2}$ elimination.

- At 1 year of age, we used standardized questionnaires to asses the outcomes: rehospitalization due to respiratory disease needing oxygen supply (excluding admissions for diagnostic purposes), wheeze and inhalation therapy with beta-agonists for more than 4 weeks.

- The association between the lung function parameters and the outcomes was assessed using non-parametric tests. Using logistic regression and receiver operating characteristic $(\mathrm{ROC})$ analysis, we determined if the predictive power of models that included BPD classification is enhanced by adding the variability of tidal breathing or capnographic parameters.

Results

- From 263 infants, 133 (51\%) were studied of which 49 had no, 34 mild, 32 moderate, and 18 severe BPD (Table 1). Of those, 61 had wheezing, 39 were rehospitalized due to respiratory disease, and home oxygen therapy was necessary in 10 .

- While the mean $\mathrm{V}_{\mathrm{T}}, \mathrm{V}_{\mathrm{E}, \mathrm{CO} 2}$ and $\mathrm{CO}_{2}$ elimination per minute did not differ between groups, all variability parameters were significantly lower in infants with subsequent rehospitalization (Figure 1). Lung function parameters did not significantly differ between the other outcomes.

- The prediction model including BPD severity only had an area under the curve (AUC) of 0.56 , adding $\mathrm{CV}_{\mathrm{VT}}$, $\mathrm{CV}_{\mathrm{VE}} \mathrm{CO}_{2}$, or the slope $\Delta \mathrm{V}_{\mathrm{E}, \mathrm{CO} 2} / \Delta \mathrm{V}_{\mathrm{T}}$ in addition to BPD better predicted rehospitalization than BPD classification alone (AUCs of $0.66,0.66$ and 0.62 ).

\begin{tabular}{|c|c|}
\hline \multicolumn{2}{|l|}{ Clinical peri- and postnatal parameters } \\
\hline Males & $77(58)$ \\
\hline Post-menstrual age at birth, weeks & $29.1 \pm 2.8(24-37)$ \\
\hline Weight at birth, $g$ & $1198.7 \pm 523(420-2980)$ \\
\hline Length at birth, $\mathrm{cm}$ & $37.9 \pm 4.2(27-50)$ \\
\hline Mechanical ventilation, days & $25.5 \pm 21.4(0-81)$ \\
\hline Weight at study date, $\mathrm{g}$ & $3883 \pm 780(1590-6800)$ \\
\hline Length at study date, $\mathrm{cm}$ & $52 \pm 3.48(39-63)$ \\
\hline Post-menstrual at study date, weeks & $44.6 \pm 1.9(40-50.3)$ \\
\hline \multicolumn{2}{|c|}{ Lung function parameters at 44 weeks post-menstrual age } \\
\hline $\mathrm{RR}, 1 / \mathrm{min}$ & $51.7 \pm 12(29-96)$ \\
\hline $\mathrm{V}_{\mathrm{T}}, \mathrm{mL} / \mathrm{kg}$ & $7.5 \pm 1.7(4.6-19)$ \\
\hline $\mathrm{CV}_{\mathrm{VT}}, \%$ & $8.5 \pm 3.6(3.7-34.9)$ \\
\hline $\mathrm{MV}, \mathrm{m} / \mathrm{kg} / \mathrm{min}$ & $373 \pm 72(229-624)$ \\
\hline $\mathrm{V}_{\mathrm{E}, \mathrm{CO} 2}, \mathrm{~m} / \mathrm{kg}$ & $0.2 \pm 0.06(0.09-0.6)$ \\
\hline $\mathrm{CV}_{\mathrm{VE}, \mathrm{CO},} \%$ & $10.3 \pm 4.1(5.3-39.7)$ \\
\hline $\mathrm{MV}_{\mathrm{CO} 2}, \mathrm{ml} / \mathrm{kg} / \mathrm{min}$ & $11.2 \pm 2.4(4.7-19.1)$ \\
\hline Slope $\Delta V_{E, C o 2} / \Delta V_{T}$ & $1.1 \pm 0.09(0.9-1.3)$ \\
\hline
\end{tabular}

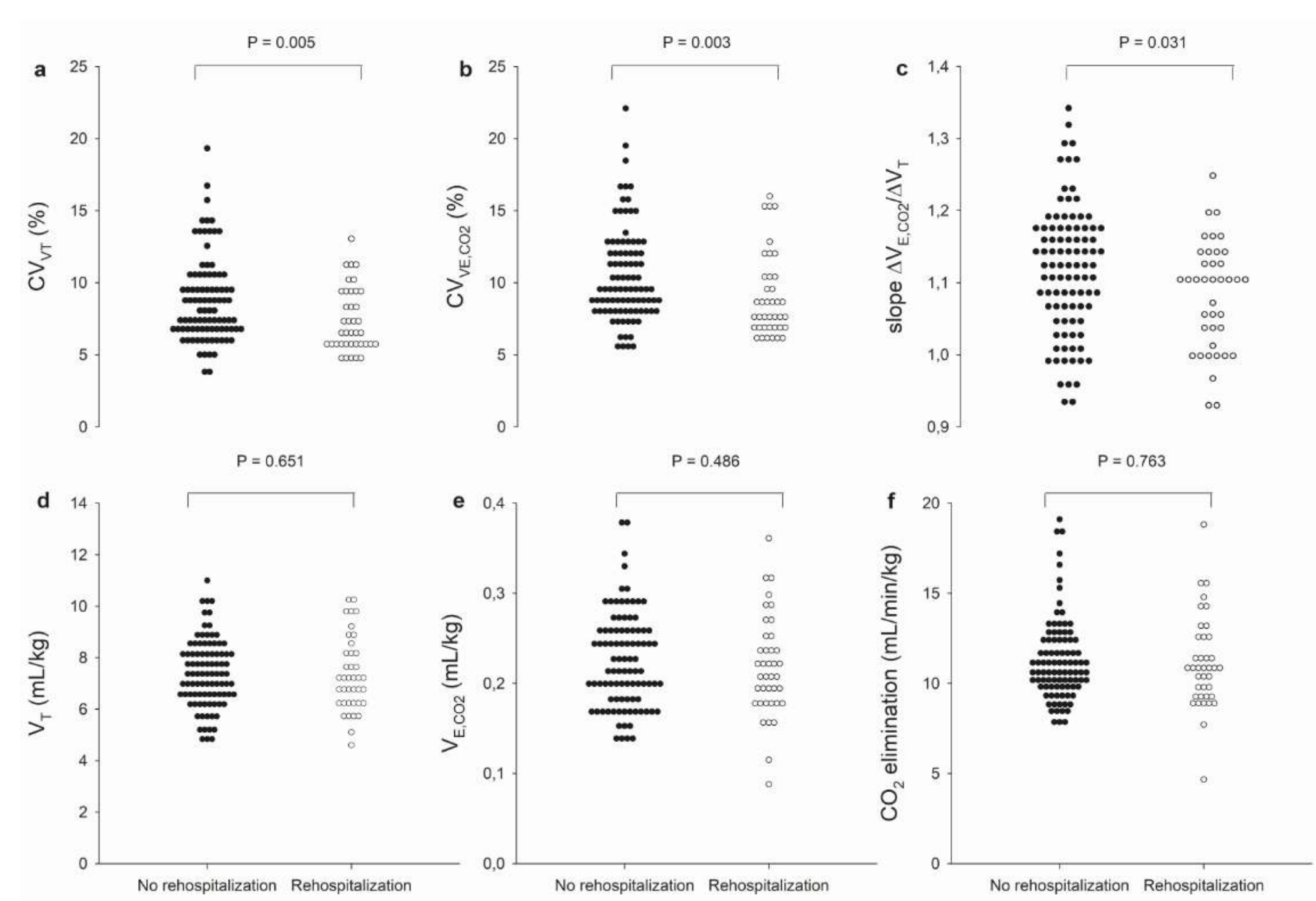

Figure 1. Comparison of lung function parameters between hospitalized and nonhospitalized preterm infants. Box plots of a) $C V_{V T}$ b) $C V_{V E, C O 2}$ c) slope $\Delta V_{E, C O 2} / \Delta V_{T} d$ ) $V_{T}$ e) $V_{E, C O 2}$ and d) $\mathrm{CO}_{2}$ elimination measured at 44 weeks post-menstrual age, stratified by the outcome rehospitalization.

- Preterm infants which require rehospitalization due to respiratory complications during the first year of life have a lower CV of several tidal breathing parameters shortly after birth.

- Variability of $\mathrm{V}_{\mathrm{T}}$ and $\mathrm{V}_{\mathrm{CO} 2}$ may be considered as simple composite, indirect markers of lung abnormalities in BPD, although functional data on lung volume or alveolar surface need to confirm this.

- The BPD score alone had a very low ability in estimating respiratory morbidity, while the addition of $\mathrm{V}_{\mathrm{T}}$ or $\mathrm{CO}_{2}$ variability to the predictive model improved its performance modestly.

- This low predictive value may indicate that other, unmeasured factors have an important influence on rehospitalisation in preterm infants. 